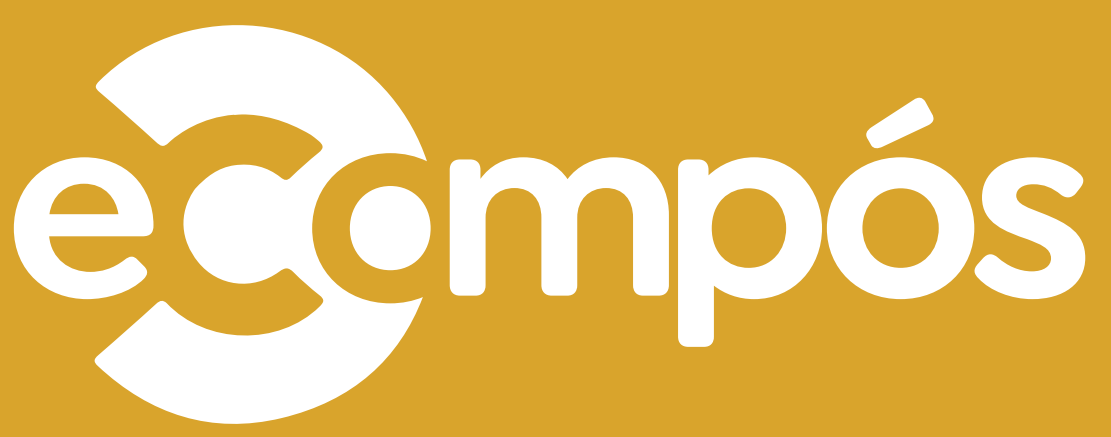

Revista da Associação Nacional dos Programas de Pós-Graduação em Comunicação

ISSN 1808-2599, v. 24, jan-dez,

publicação contínua, 2021, p. 1-19.

doi.org/10.30962/ec.2210

\title{
Fontes de informação nas redes pró e Bolsonaro sobre o coronavirus
}

\section{NINA SANTOS}

Universidade Federal da Bahia, Salvador, Bahia, Brasil
ID 2210

Recebido em $19 / 06 / 2020$ Aceito em $26 / 08 / 2020$ 


\section{/ resumo}

0 artigo analisa as fontes de informação utilizadas em um corpus de 135 mil tweets feitos com as hashtags \#Bolsonarotemrazao e \#OBrasilprecisapararBolsonaro. A partir da análise e categorização dos hiperlinks presentes nessas mensagens, investigamos as fontes de informação - entendidas como parte essencial dos processos de mediação - utilizadas na construção de diferentes discursos sobre o coronavírus e identificamos as diferenças entre os tipos de fontes mobilizadas em ambos os posicionamentos. Resultados apontam que enquanto as mensagens ligadas à hashtag pró-Bolsonaro são dominadas pela mídia alternativa, os tweets da hashtag contra ele apresentam fontes mais diversas, com maior presença das mídias tradicionais.

Palavras-chave: Coronavírus. Fontes de informação. Mediação. Twitter.

\section{De fuentes de información a mediadores: quién alimenta las redes a favor y en contra de Bolsonaro sobre el coronavirus}

Este artículo analiza las fuentes de información utilizadas en un corpus de 135 mil tweets realizados con los hashtags \#Bolsonarotemrazao o \#OBrasilprecisapararBolsonaro.Nuestro objetivo es investigar: ¿cuáles son las fuentes de información entendidas como una parte esencial de los procesos de mediación - utilizadas en la construcción de diferentes discursos sobre el Coronavirus?; ¿Cuáles son las diferencias entre los tipos de fuentes movilizadas por quienes defienden y atacan la posición de Bolsonaro? Los resultados señalan que si bien los mensajes a favor de Bolsonaro están dominados por fuentes de medios alternativas, los tweets en su contra tienen fuentes más diversas y una mayor presencia de medios tradicionales.

Palabras clave: Fuentes de información. Mediación. Twitter. Coronavirus.

\section{From information sources to mediators: who feeds the networks for and against Bolsonaro about Coronavirus}

This article analyzes the sources of information used in a corpus of 135 thousand tweets made with the hashtags \#Bolsonarotemrazao and \#OBrasilprecisapararBolsonaro. Our objective is to investigate: what are the sources of information, understood as an essential part of the mediation processes, used in the construction of different discourses about the Coronavirus?; what are the differences between the types of sources mobilized by those who defend and attack Bolsonaro's position? Results point out that while pro-Bolsonaro messages are dominated by alternative media sources, tweets against him have more diverse sources and a greater presence of traditional media.

Keywords: Information sources. Mediation. Twitter. Coronavirus. 


\section{/autora}

\section{Nina SANTOS}

Doutora em Ciências da Informação e da Comunicação pela Université PanthéonAssas / Paris II. Pós-doutoranda no Instituto Nacional de Ciência e Tecnologia em Democracia Digital. Pesquisadora associada do Centro de Análise e Pesquisa Interdisciplinar em Mídia da Université Panthéon-Assas / Paris II.

Universidade Federal da Bahia, Salvador, Bahia, Brasil.

E-mail: ninocasan@gmail.com

\section{ORCID}

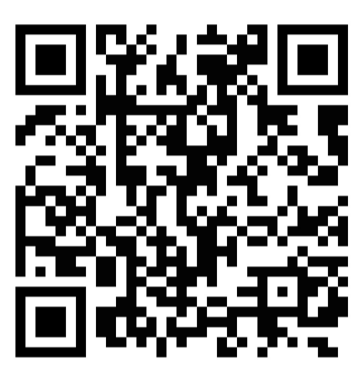




\section{Introdução}

A pandemia do novo coronavírus (Sars-CoV-2), iniciada em março de 2020, pegou o mundo de surpresa e mudou radicalmente a rotina de milhões de pessoas ao redor do globo. As dinâmicas sociais e comunicacionais que emergiram desse momento tão peculiar da história, no entanto, não são completamente novas. Momentos de crise tanto podem servir para intensificar e tornar mais visiveis práticas que estavam em processo de disseminação nas sociedades, quanto para adicionar novos elementos, mudanças de rumo a esses mesmos processos. Nesse contexto, a crise epistêmica já apontada por diversos autores (BENKLER; FARIS; ROBERTS, 2018; GOMES; DOURADO, 2019) como uma característica dos nossos tempos ganha ainda mais centralidade no debate político.

No Brasil, o ataque a tradicionais instituições democráticas, como as universidades, a imprensa e as instituições políticas, já tinha se tornado corrente no mundo político antes da crise. Discursos como o do terraplanismo e o do negacionismo climático já circulavam na sociedade, mas o coronavírus inaugura um novo episódio dessa questão. Ao mesmo tempo em que há um avanço de discursos que desprezam completamente o papel de instituições sociais, especialmente da ciência, diversas pesquisas indicam também uma certa retomada do papel de mediação de alguns atores, sobretudo dos meios de comunicação tradicionais (NIELSEN et al., 2020). Em um contexto com consequências muito concretas e imediatas - as mortes por Covid-19 são de muito mais fácil aferição direta pelos cidadãos do que a forma do planeta Terra, por exemplo -, o presidente brasileiro Jair Bolsonaro opta por radicalizar ainda mais seus posicionamentos de descrença e ataque às instituições, defendendo ações que vão na direção contrária de todas as organizações médicas e científicas e também da enorme maioria das experiências internacionais'.

O pronunciamento à nação feito por Bolsonaro em rede nacional de rádio e televisão na noite do dia 24 de março é um marco no posicionamento adotado pelo político². Na ocasião, em um discurso que ataca a imprensa e não cita nenhuma fonte externa ao próprio governo, o presidente defende o fim do isolamento social incitando as pessoas a "voltarem à normalidade" chamando o coronavírus de "gripezinha ou resfriadinho". o que nos interessa aqui, no entanto, não são as motivações ou estratégias discursivas do presidente, ainda que as mesmas sejam um ponto crucial a ser debatido. Nosso foco está no momento posterior ao pronunciamento, quando as mídias sociais, e notadamente o Twitter, foram palco de milhares de mensagens sobre a fala do presidente.

No dia seguinte ao pronunciamento, a hashtag \#Bolsonarotemrazão aparecia entre os temas mais comentados do país e, em reação a ela, nos dias que se seguiram, apareceu também a hashtag \#OBrasilprecisapararBolsonaro. Com intenções claramente opostas entre si, essas duas hashtags foram amplamente utilizadas para compartilhar mensagens. Então, as duas questões centrais que motivam este texto são: em meio a um ataque tão forte e sistemático às tradicionais instituições democráticas, quais são as fontes de informação que funcionam como mediadores na construção de diferentes discursos sobre o coronavírus? Quais as diferenças entre os tipos de fontes mobilizados por aqueles que postam mensagens com hashtags que defendem e atacam o posicionamento de Bolsonaro?

10 primeiro caso de coronavírus no Brasil foi registrado no dia 26 de fevereiro, quase 2 meses depois da divulgação do primeiro caso na China e semanas após os primeiros casos europeus, em países como Alemanha, Itália e França. Isso permitiria ao Brasil conhecer as diversas trajetórias de disseminação da doença de acordo com as diferentes medidas adotadas por esses países. Ao contrário disso, as experiências foram desprezadas ou desacreditadas como informações válidas para auxiliar no posicionamento do presidente.

2 A íntegra do pronunciamento pode ser vista no canal do Youtube do Palácio do Planalto: Disponível em: <https://www.youtube.com/watch?v=Vl_ DYb-XaAE>. Acesso em: 21 jul. 2020. 
Para avaliar tais questões, coletamos tweets postados com as duas hashtags utilizadas. Com o total de 135 mil mensagens, analisamos a quem eles recorrem como fontes de informação e delineamos uma categorização dessas fontes. Antes de apresentar os resultados da avaliação realizada, discutiremos brevemente a noção de mediação e a sua relação com a análise de fontes de informação.

\section{Mediação e fontes de informação}

A decisão de analisar as fontes de informação presentes em diferentes posições de um debate político se justifica por permitir-nos apreender parte importante dos processos de mediação que marcam as atuais dinâmicas comunicacionais. Consideramos que é preciso ir além na compreensão desses dados. Não se tratam apenas de indicações sobre fontes de informação mais utilizadas, mas sim sobre mediadores sociais a quem se atribui legitimidade para produzir informações sobre determinada questão. A multiplicidade de atores no ambiente digital permite que essa legitimidade seja atribuída de formas diversas por grupos sociais, o que gera processos de visibilidade distintos.

Em um contexto de crise epistêmica, mais do que compreender o papel de cada mídia, tornase essencial avaliar quais mídias são reconhecidas e legitimadas como mediadoras de informação por diferentes grupos sociais para, em seguida, explorar como essa mediação é feita, já que os parâmetros jornalísticos já não são mais os únicos no horizonte. Como defende Sonia Livingstone (2009), o interesse pelos processos de mediação permite essencialmente revelar as mudanças relativas às interações entre estruturas sociais e seus agentes, mais do que aquelas sobre as mídias em si mesmas. Esse foco na mediação - não no tradicional sentido dado à palavra na academia brasileira, como ligado aos processos de negociação de sentidos e recepção (LIVINGSTONE, 2009), mas sim como o papel dos atores midiáticos que se colocam entre os fatos e os cidadãos - permite-nos analisar de forma não-fragmentada fenômenos importantes do cenário comunicacional e político atual. Vale ressaltar que tal perspectiva tem sido desenvolvida também por trabalhos brasileiros mais recentes, que têm destacado o papel dos processos de mediação comunicacional e das fontes de informação na estruturação de um debate democrático (LEMOS, 2020; LYCARIÃO, 2014; MORAES; ADGHIRNI, 2012; SILVA; MUNDIM, 2015).

Identificar fontes de informação, portanto, vai além do fato de conhecer relações entre mídias ou para onde urls apontam. Fontes de informação funcionam como mediadoras a quem se recorre como autoridade na difusão de informações. É justamente nessas relações de legitimidade, visibilidade e autoridade - pilares que também assentam a representação democrática - que acreditamos estar uma chave importante para entender os fluxos comunicativos e seus impactos políticos atuais. Certamente, o contexto de pandemia e a politização desse tema no Brasil deixam tais questões ainda mais em evidência, mas elas não estão restritas a esse momento e podem fornecer pistas essenciais para compreender os processos políticos contemporâneos.

A questão da mediação ${ }^{3}$ emerge concomitantemente aos meios de comunicação de massa, quando os processos de visibilidade passam a ser mediados e deixam de se limitar ao aqui e agora (THOMPSON, 2005). É, portanto, a possibilidade de obter conhecimento de informações que não são depreendidas da própria experiência, mas sim de um sistema de comunicação, que faz com que o debate sobre o papel desses mediadores comunicacionais se torne central. Durante muito tempo, portanto, essa discussão esteve ligada quase exclusivamente ao papel dos jornalistas e dos meios de comunicação tradicionais como atores sociais legitimados para selecionar o que merecia ser divulgado para o grande público. Nesse sentido, o

3 É importante ressaltar que não atribuímos aqui nenhum sentido intrinsecamente negativo ao processo de mediação (SANTOS, 2010), sendo, portanto, parte da construção da realidade e não um processo que envolve uma perda de em relação ao real (RUBIM, 2002). 
debate sobre mediação aproxima-se de questões sobre o papel dos jornalistas como gatekeepers (MERAZ; PAPACHARISSI, 2013; SEGERBERG; BENNETT, 2011; SHOEMAKER et al., 2001).

Com a emergência da web 2.0 e os novos atores que passam a compor a polifonia de vozes nas redes digitais (LEMOS, 2008), esse debate se complexifica e dá origem a novas interpretações do fenômeno que podem ser agrupadas em torno de três linhas centrais. o primeiro foco de análise vai se concentrar no fato de que não é mais necessário passar por instituições jornalísticas para falar a determinados públicos e isso resultaria, portanto, na chamada desintermediação. 0 debate ganha força na primeira década dos anos 2000, com os blogs (ALDÉ; ESCOBAR; CHAGAS, 2006; PENTEADO; SANTOS; ARAUJO, 2009; SANTOS, 2010), e continua a se desenvolver com as mídias sociais (ELDRIDGE II; GARCÍA-CARRETERO; BROERSMA, 2019; GERBAUDO, 2012) e aplicativos de mensagens instantâneas, sempre focando na possibilidade de uma suposta comunicação direta entre um determinado emissor e seu público, dispensando a ação das mídias tradicionais. Dessa concepção decorrem conceitos amplamente usados como o de "mass self-communication" (CASTELLS, 2009) e o "personal publics" (SCHMIDT, 2014).

Uma segunda linha de análise da questão da mediação, que decorre da primeira, tem se dedicado a avaliar os novos mediadores que emergem nesse contexto de expansão das novas mídias. Assim, já que os meios de comunicação tradicionais não detêm mais o controle quase exclusivo da esfera de visibilidade pública, quem são e como emergem esses novos atores capazes de gerar visibilidade social? (BASTOS; MERCEA, 2015; GARCIA; TRERE, 2014; RODRÍGUEZ; FERRON; SHAMAS, 2014). Já uma terceira linha interpretativa da questão da mediação vai se concentrar em compreender o papel de mediadores que vai além daquele que emite ou dissemina uma informação. Esses estudos vão focar no papel de uma série de elementos tecnológicos que passam a fazer parte dos processos de mediação, como as próprias plataformas e seus algoritmos de organização de conteúdo (LEMOS, 2020; HEPP, 2020), mas também em novos papéis que as próprias pessoas passam a ter nos processos de disseminação informativa (GOMES, 2016; SANTOS, 2019).

Embora normativamente a separação entre essas três linhas interpretativas possa nos ajudar a compreender as diferentes abordagens do fenômeno, empiricamente é o entrelaçamento delas que tem se mostrado mais frequente. Diversos estudos revelam que as mídias tradicionais continuam a exercer papel importante no ecossistema midiático, inclusive na repercussão de mensagens de líderes e organizações que se comunicam essencialmente via mídias sociais (MITOZO; COSTA; RODRIGUES, 2020; NEWMAN et al., 2019; STIER; SCHÜNEMANN; STEIGER, 2018). Nesse sentido, o papel dos mediadores alternativos pode ficar restrito a determinados círculos sociais. Por isso, ao invés de considerar o ambiente digital como fonte de uma horizontalidade, parece mais profícuo compreender as especificidades dos novos tipos de verticalidades trazidos por ela (GERBAUDO, 2020; JOATHAN; ALVES, 2020).

A abordagem proposta por Chadwick (2013) é especialmente interessante, na medida em que concebe esse novo ecossistema midiático como um espaço de convivência e interação entre não apenas diversos meios, mas sobretudo diversas lógicas comunicacionais. Para o autor, a novidade trazida por esse ambiente emerge não da tecnologia em si, mas sim das diferentes combinações possiveis entre novas e antigas lógicas de comunicação que interagem nesse novo cenário. Portanto, olhar para os atuais processos de mediação implica em considerá-los como entrelaçamento de um complexo de atores com diversas lógicas que funcionam como instância intermediária entre as pessoas e a percepção que constroem do mundo.

Como exposto anteriormente, pensar a mediação comunicacional em um momento de crise epistêmica torna-se ainda mais desafiador. Em um contexto em que é difícil achar consensos sobre quem é capaz de produzir conhecimento e estabelecer a verdade, as fontes de informação tornam-se elementos centrais. Através delas conseguimos averiguar tanto o papel dos tradicionais meios de comunicação, quanto a valorização de eventuais novos mediadores que passam a servir de base para a construção de determinados discursos. Desse modo, a análise das fontes de informação mostra-se um ponto de partida promissor para compreender os atuais processos de mediação comunicacional. 


\section{Metodologia}

Operacionalizar a visão dos processos de mediação acima apresentada do ponto metodológico apresenta uma série de desafios, tanto do ponto de vista da construção de instrumentos de análise quanto da possibilidade de obtenção de dados que nos permitam uma análise mais completa do percurso informativo. Neste texto, tentaremos aprofundar esse debate a partir de uma análise dos links utilizados em mensagens postadas no Twitter.

A ideia de olhar para os hiperlinks compartilhados em uma determinada rede social digital, ainda que bastante restrita frente ao desafio colocado pela complexidade dos processos de mediação, funciona como indício de uma série de processos. Como propõem Meraz e Papacharissi (2013), nas mídias sociais é possivel pensar em um processo de gatekeeping em rede. Segundo elas, essa releitura do conceito incorporaria um processo multinivel que inclui novos atores com niveis diversos de poder. Outra diferença da conceitualização tradicional dos gatekeepers é que ela considera a sociabilidade como uma nova variável no fluxo de informações. As autoras usam as categorias elite e não elite para descrever os diferentes atores em interação nesse processo de seleção de informações, e a novidade é que os atores que formam a não elite agora têm mais possibilidades de decisão em relação ao fluxo informacional.

Outra forma de ver essa junção diversa de processos de mediação é apresentada por Segerberg e Bennet (2011, p. 202), que vão ressaltar que os fluxos do Twitter, ao mesmo tempo “incorporam e são incorporados nos processos de gatekeeping". Eles ressaltam que, ao mesmo tempo em que o Twitter tem seus processos mediadores específicos - a própria plataforma, seus algoritmos de organização e filtragem de informação e as redes sociais ali estabelecidas -, o fluxo comunicativo dos tweets também depende de mediadores externos que vão fornecer conteúdos que serão compartilhados na plataforma.

Considerando essas duas abordagens, é possivel dizer que a compreensão da forma como links são compartilhados no Twitter permite um entendimento sobre uma série de processos que estão subjacentes à essa escolha. Portanto, apesar de se concentrar exclusivamente no Twitter como plataforma de exploração, a análise de links tem como objetivo justamente olhar, ao mesmo tempo, para processos internos da plataforma e para o entorno dela, ou seja, para o ecossistema onde ela está inserida.

Ressaltamos que a escolha desse ambiente comunicativo não tem como intuito analisá-lo de forma isolada ou considerá-lo como representativo de todo o sistema midiático, pelo contrário. Reconhecemos a necessidade premente de não considerar mídias de forma isolada e de compreender a lógica de sistema que rege o funcionamento midiático atual (CHADWICK, 2013). O Twitter, portanto, por ser um ambiente de comunicação especialmente utilizado para o debate político e a troca de mensagens políticas em tempo real ${ }^{4}$, funciona como ponto de partida da nossa investigação.

Os dados que analisamos aqui são fruto de coletas de mensagens com duas hashtags. 0 primeiro corpus é composto de 98.141 mensagens postadas entre às $22 \mathrm{~h}$ do dia 25 de março de 2020 e às $11 \mathrm{~h}$ do dia 27 de março do mesmo ano (total de 37 horas de coleta) com a hashtag \#Bolsonarotemrazao. Já o segundo corpus reúne 37.573 tweets postados com a hashtag \#OBrasiltemquepararBolsonaro, publicados em período posterior, já que essa hashtag surgiu em reação à primeira. Essas mensagens foram coletadas entre às $20 \mathrm{~h}$ do dia 27 de março de 2020 e às $9 \mathrm{~h}$ do dia 29 de março do mesmo ano (totalizando as mesmas 37 horas de coleta). Essas duas hashtags foram escolhidas por terem sido amplamente utilizadas - ambas estiveram entre os temas mais comentados do Twitter - e representaram posicionamentos opostos em relação ao discurso do presidente Jair Bolsonaro no pronunciamento à nação feito no dia 24 de março de 2020.

4 Por limitações de espaço, não poderemos retomar o histórico do Twitter como plataforma preferencial para debates políticos e coberturas em tempo real. Um debate mais aprofundado sobre o tema pode ser encontrado no livro Twitter and Society, editado por Katrin Weller, Axel Bruns, Jean Burgess, Merja Mahrt e Cornelius Puschmann e publicado em 2014. 
As hashtags ampliam o público de um tweet para muito além do círculo inicial de seguidores de um determinado usuário. Também identificam a mensagem em relação a um certo problema e ajudam a organizar a conversa em torno de tópicos importantes. Além disso, elas "sinalizam o desejo de participar de um processo comunicativo mais amplo" (BRUNS; MOE, 2014, p. 18), o que torna possivel reunir diferentes públicos em torno de um mesmo tópico. No caso de hashtags associadas a determinados eventos políticos ou sociais, a linha do tempo pode funcionar como uma certa narrativa do evento, construída por diferentes e múltiplas informações e opiniões (BRUNS; MOE, 2014). Devemos considerar, no entanto, que os usuários que usam uma hashtag não seguem necessariamente a linha do tempo da conversa sobre essa palavrachave, o que significa que o uso da hashtag pode, em alguns casos, funcionar mais como marcador do que como engajamento em uma causa.

A coleta foi feita utilizando o script Get Tags ${ }^{5}$, que extrai tweets a partir da API da plataforma e, portanto, tem limitações na quantidade de mensagens. Configuramos a extração para acontecer todas as horas. Ou seja, a cada hora, foram coletadas o limite de mensagens permitido pela API. Nosso corpus, portanto, não tem a pretensão de representar a totalidade de mensagens postadas sobre o tema, mas sim uma amostra delas. Para o processamento, a análise e a visualização dos dados foram utilizados os softwares Tableau e R, com apoio do Microsoft Excel.

Para responder nossa questão de pesquisa sobre as fontes de informação a quem se recorre como mediadores de discursos para falar sobre as medidas de combate ao Coronavírus, realizamos uma análise em duas etapas. A primeira é centrada nos tipos de hiperlinks presentes nas mensagens. Assumimos que os links têm um papel não apenas no fluxo de informação, mas também nas formas de organização de determinados discursos (SEGERBERG; BENNETT, 2011). Além disso, os links funcionam como ligações entre diferentes atores do ecossistema comunicativo, permitindo uma análise que vai além das mídias em si.

Nesse sentido, analisamos o uso de links nos nossos dois corpora de tweets e identificamos a fonte à qual eles apontam. Esses links foram separados inicialmente em 6 categorias, que são detalhadas a seguir:

- Mídia tradicional: foram considerados sites de mídia tradicional todos aqueles ligados a grandes empresas de mídia que têm pelo menos um veículo de televisão, jornal, revista ou rádio.

- Mídia alternativa: consideramos como mídias alternativas aquelas produzidas fora de instituições e redes de mídias tradicionais ${ }^{6}$ (ATTON; COULDRY, 2003). Se, por um lado, algumas dessas mídias podem ser vistas como geradoras de processos de fortalecimento das relações entre mídia e sociedade civil (WAISBORD, 2009), por outro, elas também têm sido apontadas como atores importantes em processos de desinformação, especialmente quando caracterizadas pela hiperpartidarização (RECUERO; SOARES, 2020).

- Mídia regional: como destaca Peruzzo (2005), a história das mídias locais e regionais aproxima-se daquela das mídias comunitárias, dada a importância delas para a construção de um sentido de comunidade em um determinado território. Portanto, elas foram consideradas uma categoria à parte (não sendo possivel classificá-las entre tradicionais e alternativas) pela especificidade das suas relações com as redes locais, que diferem dos veículos de amplitude nacional.

5 Disponivel em: <https://tags.hawksey.info/get-tags/>. Acesso em: 21 jul. 2020.

6 A escolha por um conceito amplo de mídias alternativas não tem por objetivo desconsiderar a longa tradição de estudos nessa área e os esforços feitos no sentido de construir caracterizações mais precisas das relações dessas mídias tanto com os meios de comunicação tradicionais, quanto com os movimentos sociais e a sociedade de forma mais ampla. Para uma leitura mais refinada sobre esse debate, ver Ferron (2010), Waisbord (2009) e Suzina (2019). Neste texto, trabalhamos com uma aproximação inicial à presença dessas mídias no corpus analisado, que certamente merecerá ser refinado em momento posterior, tanto pela diversidade dos sites quanto pelos desafios que seus modelos representam para as tradicionais categorias desse campo de estudos. 
- Mídias sociais: adotamos a clássica definição de Boyd e Elisson (2007, p. 211) de que sites de mídias sociais "permitem aos indivíduos (1) construir um perfil público ou semipúblico dentro de um sistema limitado, (2) articular uma lista de outros usuários com quem esses usuários dividem uma conexão e (3) ver suas listas de conexões e aquelas feitas por outros no sistema". Contudo, considerando o crescimento considerável do uso dessas mídias a partir de dispositivos móveis (CANAVILHAS; RODRIGUES, 2017), incluímos também o acesso a tais plataformas a partir de aplicativos e não de sites.

- Organizações: sites de instituições estatais ou organizações da sociedade civil, incluindo sites de partidos políticos ou de políticos.

- Outros: aqueles que não se encaixam em nenhuma das categorias anteriormente apresentadas.

Como explicado na introdução deste artigo, o pronunciamento do presidente Jair Bolsonaro do dia 24 de março de 2020 ia contra todas as recomendações de combate ao coronavírus amplamente aceitas por órgãos de saúde internacionais e divulgadas pela mídia tradicional. Como mostram Nielsen et al. (2020), apesar da busca por informação nos meios tradicionais em geral crescer no contexto de pandemia, no caso dos Estados Unidos, a confiança nessa fonte de informação tende a ser menor entre os eleitores de direita, mais próximos do presidente Donald Trump, que adotou uma postura em relação à pandemia similar à de Jair Bolsonaro. Também um estudo recente de Recuero e Soares $(2020$, p. 22) mostra uma importante conexão entre as redes de discursos sobre o coronavírus e aquelas de informação política. Os autores mostram como os discursos do presidente Jair Bolsonaro impactam a circulação de notícias falsas e como se articulam as redes de reação a elas. Segundo eles:

as mensagens que desmentiam informações [falsas] eram principalmente produzidas por líderes de opinião como jornalistas e pesquisadores, que produzem conteúdo mais técnico, e influenciadores de conteúdo, como veículos jornalísticos; enquanto a desinformação era principalmente produzida por líderes de opinião associados a agendas políticas, como políticos e comentadores de política, além de veículos hiperpartidários.

Com base nisso, supomos que as mensagens de apoio a Bolsonaro se apoiarão menos em fontes de informação em geral e em fontes dos meios de comunicação tradicional em específico. Daí decorrem nossas duas primeiras hipóteses:

H1: o corpus de mensagens com a hashtag \#OBrasilprecisapararBolsonaro apresentará proporcionalmente mais links do que aquele da hashtag \#Bolsonarotemrazão.

H2: os tweets que usam a hashtag \#Bolsonarotemrazão se apoiam menos em links que levam a fontes ligadas aos meios de comunicação tradicionais do que aqueles que se manifestaram com a hashtag \#OBrasiltemquepararBolsonaro. Além disso, dada a importância dos "líderes de opinião associados a agendas políticas, como políticos e comentadores de política, além de veículos hiperpartidários" (RECUERO; SOARES, 2020) no reforço de discursos de apoio a Bolsonaro, acreditamos que as mídias sociais serão fontes frequentemente citadas entre as mensagens com a hashtag \#Bolsonarotemrazão. Considerando que as mídias sociais são espaços que permitem a emergência e a disseminação de vozes dissonantes dos meios tradicionais (CHADWICK, 2013; MERAZ; PAPACHARISSI, 2013), acreditamos que as mesmas serão frequentemente apontadas como fontes de informação entre aqueles que postam com a hashtag de apoio ao presidente. Daí nossa terceira hipótese: 
H3: a categoria mídia sociais será percentualmente mais relevante no corpus \#Bolsonarotemrazão que nas mensagens relativas a \#OBrasiltemquepararBolsonaro.

\section{Análise e resultados}

Com o intuito de testar nossa primeira hipótese, analisamos a frequência do uso de hiperlinks nos dois corpora selecionados. Em seguida, olhamos quais os domínios dos links mais compartilhados ${ }^{7}$ em cada uma das nossas amostras. O que nos interessa aqui não é o compartilhamento de um conteúdo específico, mas sim a identificação da recorrência do uso de determinadas fontes de informação nos tweets ${ }^{8}$.

Como mostra a Tabela 1, a taxa de links externos é significantemente maior nos tweets com a hashtag que defende as propostas de Bolsonaro, o que refuta nossa primeira hipótese. Enquanto o corpus de mensagens com a hashtag de apoio ao presidente apresenta $8,6 \%$ de suas mensagens com links externos ao Twitter, entre aqueles que criticam Bolsonaro essa taxa é de 4,9\%. O fato de a quantidade de tweets com links ser quase duas vezes maior entre as mensagens com a hashtag \#Bolsonarotemrazão parece apontar para uma maior busca dos usuários que a utilizam por uma validação externa de seus discursos, fenômeno que parece menos comum no grupo daqueles que usam a hashtag \#OBrasiltemquepararBolsonaro.

Tabela 1: Uso de links externos nos dois corpora

\section{\#Bolsonarotemrazão}

Tweets

Tweets com links

Porcentagem do total

\section{Tabela 1: Uso delinks ext}


Já na segunda análise, consideramos a quantidade de vezes em que cada um dos sites aparece nos tweets da amostra, ou seja, também levamos em conta aqui a taxa de replicação de cada link. Nessa etapa, foram considerados os 8.566 tweets com links externos da amostra \#Bolsonarotemrazao e 1.847 tweets com links externos da amostra \#OBrasilprecisapararBolsonaro.

No corpus de tweets da hashtag de apoio a Bolsonaro, podemos ver que os dois tipos de sites mais frequentes são aqueles com conteúdo considerado de veículos de mídia alternativa e aqueles da mídia tradicional (ambos com 28,69\%). Em seguida, aparecem os sites da mídia regional (18,85\%). Quando consideramos a disseminação desses links, no entanto, ou seja, a quantidade de vezes que eles são replicados, a diferença entre as categorias torna-se muito mais evidente. A mídia alternativa passa a representar $78,78 \%$ dos links, enquanto a mídia tradicional cai para $10,26 \%$ e a regional para $2,20 \%$. Além da mídia alternativa, a única outra categoria que é mais representativa quando se considera a sua disseminação são os links para mídias sociais, que passam de $4,29 \%$ para $8,31 \%$.

Tabela 2: Categorias dos domínios e dos tweets com links - \#Bolsonarotemrazão

$\left.\begin{array}{|lcc|}\hline \multicolumn{1}{c}{\text { Categoria }} & \begin{array}{c}\% \text { de sites } \\ (\mathbf{n}=22)\end{array} & \begin{array}{c}\% \text { dos tweets } \\ \text { com links (n=8566) }\end{array} \\ \hline \text { Mídia Alternativa } & 28,69 \% & 78,78 \%\end{array}\right)$

Fonte: Elaborada pela autora (2020).

Ao fazer a mesma análise no corpus de mensagens postadas com a hashtag de críticas a Bolsonaro, encontramos resultados muito semelhantes quando consideradas as porcentagens de cada categoria em relação ao total de sites. Apenas as categorias da mídia tradicional e da mídia regional apresentam diferenças significativas. Enquanto a primeira é maior (36,43\%), a segunda apresenta-se menor (14,95\%).

Essa semelhança se dissipa, no entanto, quando consideramos as taxas de replicação desses links. Nesse caso, é a categoria da mídia tradicional que cresce, passando de $36,43 \%$ para $48,02 \%$, juntamente com os links que levam para páginas de organizações, que passam de 5,43\% para 16,46\%. Importante ressaltar que, nessa última categoria, aparecem links para sites de organizações políticas ou de políticos, algo que não acontece no corpus de apoio a Bolsonaro. A categoria de mídia alternativa, que representa $25,58 \%$ do total de sites que aparecem na amostra, representa apenas $22,58 \%$ dos tweets com links. 
Tabela 3: Categorias dos domínios e dos tweets com links - \#OBrasilprecisapararBolsonaro

\begin{tabular}{|lcc|}
\hline \multicolumn{1}{c}{ Categoria } & $\begin{array}{c}\% \text { de sites } \\
(\mathrm{n}=129)\end{array}$ & $\begin{array}{c}\% \text { dos tweets } \\
\text { com links }(n=1847)\end{array}$ \\
\hline Midia Alternativa & $36,43 \%$ & $48,02 \%$ \\
\hline Midia Tradicional & $25,58 \%$ & $22,58 \%$ \\
\hline Midia Regional & $13,95 \%$ & $1,79 \%$ \\
\hline Outros & $13,18 \%$ & $3,09 \%$ \\
\hline Organizações & $5,43 \%$ & $8,07 \%$ \\
\hline Midias Sociais & $5,43 \%$ & $16,46 \%$
\end{tabular}

Fonte: Elaborada pela autora (2020).

Os resultados sugerem que, apesar de partir de bases com categorias das fontes de informação distribuídas de modo muito similar, os dois corpora apresentam padrões bastante diferentes de disseminação dessa informação. Dessa forma, nossa segunda hipótese foi confirmada. As mídias tradicionais representaram uma porcentagem superior nas mensagens da hashtag \#OBrasilprecisapararBolsonaro tanto em relação ao número de sites (36,43\% x 29,69\%), quanto à quantidade de mensagens com links (48,02\% x 10,26\%).

Em relação à terceira hipótese, no entanto, não há confirmação. O uso das mídias sociais como fontes de informação externas ao Twitter é muito parecido entre os dois corpora, nas duas dimensões analisadas. Enquanto a porcentagem de sites de mídias sociais é levemente maior entre as mensagens com a hashtag \#OBrasilprecisapararBolsonaro (5,43\% x 4,92\% em \#Bolsonaro tem razão), a relação se inverte, mas permanece muito parecida quando se leva em conta a disseminação desses links ao longo dos tweets - 8,07\% nas mensagens de \#OBrasilprecisapararBolsonaro x 8,31\% em \#Bolsonarotemrazão).

Além disso, enquanto as mensagens com a hashtag de apoio a Bolsonaro tendem, em sua grande maioria, a replicar tweets com links para mídias alternativas, aquelas com a hashtag de crítica ao presidente apresentam uma diversidade maior na replicação e se concentram principalmente em torno da mídia tradicional. Essa diferença também fica clara quando olhamos especificamente para a lista de domínios compartilhados nos dois corpora. Enquanto nas mensagens relacionadas à hashtag \#Bolsonarotemrazao, o Jornal da Cidade Online, que é o mais compartilhado, é responsável por 73,5\% dos links para fontes externas ao Twitter, nos tweets da hashtag \#OBrasilprecisapararBolsonaro os links mais compartilhados, relacionados ao portal UOL, representam $20,7 \%$ do total. 


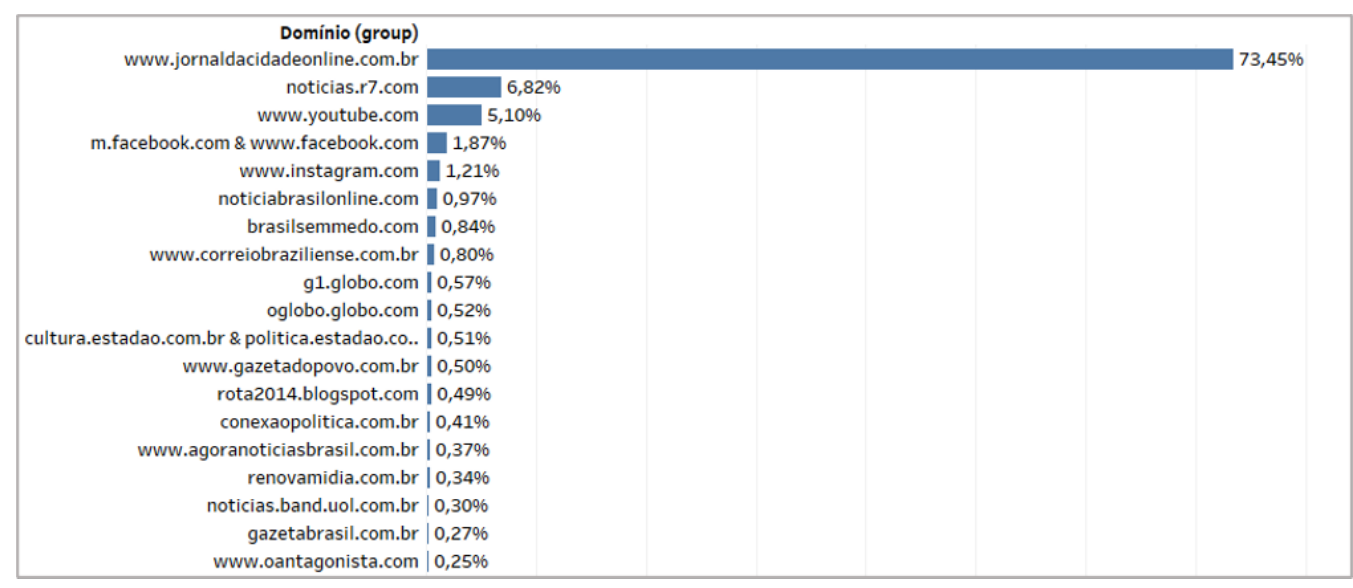

Figura 01: Sites mais compartilhados com a hashtag \#Bolsonarotemrazao

Fonte: Elaborado pela autora (2020).

Essa grande relevância das mídias alternativas no corpus de mensagens da hashtag \#Bolsonarotemrazão parece demonstrar que, diferentemente do que supúnhamos, os “líderes de opinião associados a agendas políticas, como políticos e comentadores de política, além de veículos hiperpartidários" apontados por Recuero e Soares (2020) como atores-chave para esse discurso, não são referenciados no Twitter a partir de seus perfis em mídias sociais, mas sim diretamente de sites. Isso aponta para a importância central deste novo ecossistema midiático que não está baseado nem nos meios tradicionais, nem nas mídias sociais, mas que tem servido fortemente para subsidiar um determinado tipo de discurso no debate nas plataformas sociais.

\section{Considerações Finais}

O estudo apresentado aqui permite-nos perceber indicativos importantes do atual sistema midiático (CHADWICK, 2013). As análises dos links mais usados nos tweets postados com hashtags de apoio e de crítica ao pronunciamento do dia 24 de março do presidente Jair Bolsonaro partem de uma base muito semelhante de sites. A comparação entre os tipos de sites que aparecem nos dois corpora mostra que ambos mencionam informações de fontes semelhantes. Essa similaridade não se mantém, no entanto, quando a unidade de medida considera a quantidade de vezes que cada uma das fontes aparece nos corpora. Nesse caso, enquanto as mídias alternativas dominam de maneira quase absoluta (79\%) o corpus da hashtag \#Bolsonarotemrazao, as mensagens de \#OBrasilprecisapararBolsonaro apresentam uma maior distribuição entre diferentes fontes, com destaque para as mídias tradicionais (48\%) e as mídias alternativas (23\%). Importante ressaltar ainda que as fontes de informação dos dois corpora coincidem em $1 / 3$ das fontes citadas.

Desses resultados decorrem três achados que nos parecem relevantes. 0 primeiro diz respeito à diferença de tratamento das mídias tradicionais como mediadoras em públicos com diferentes posições políticas. A menor disseminação de informações desses meios em nosso corpus de mensagens que apoiam Bolsonaro parece alinhada com os frequentes e agressivos ataques do presidente à imprensa e ao jornalismo em geral. O fenômeno, contudo, não é apenas brasileiro. Recente pesquisa do Reuters Institute (NIELSEN et al., 2020), feita durante a pandemia da Covid-19, mostra o consumo e a confiança das pessoas em diversas fontes de informação e instituições. Ao cruzar os dados sobre posicionamento político nos Estados Unidos com aqueles de confiança em fontes de informação, os pesquisadores encontraram que enquanto entre 
aqueles que se declaravam de esquerda (70\%) diziam confiar nas organizações midiáticas, essa taxa caia pela metade entre os que se diziam de direita. Já a confiança em "pessoas que eu conheço" era de $43 \%$ entre as pessoas de esquerda e subia para $48 \%$ entre quem se declarava de direita.

Essa tendência de menor confiança e disseminação de informações da mídia tradicional entre aqueles que se declaram de direita, que na nossa amostra estariam claramente reunidos entre os que usam a hashtag \#Bolsonarotemrazao, não deixa de levantar questões sobre a realidade brasileira. É preciso considerar que, no Brasil, a crítica à mídia se construiu historicamente como uma pauta da esquerda, desde a luta pela liberdade de imprensa durante a ditadura militar até as lutas contra a concentração da mídia após a democratização. Em 2013, contudo, já era possivel perceber que as críticas à mídia, sobretudo à Rede Globo, já haviam se disseminado pela sociedade, fazendo com que ela fosse acusada ao mesmo tempo de tentar derrubar e trabalhar pela reeleição da presidente Dilma Rousseff (SANTOS; ALMADA, 2019). Aparentemente, esse processo se aprofundou nos últimos anos, fazendo com que a crítica à mídia tradicional torne-se ainda mais proeminente no campo de direita, o que possivelmente tem relação com o fato desse campo político ter chegado à Presidência da República.

De toda forma, a crítica à mídia tradicional combinada com as potencialidades da web 2.0 nos leva ao nosso segundo achado, que diz respeito a um novo ecossistema de mídias alternativas que passa a ocupar lugar central no processo de mediação. Longe de ser novidade, as mídias que se constroem fora ou em oposição às mídias mainstream sempre existiram, desde os fanzines, passando pelos jornais dos sindicatos e chegando aos blogs online. A questão, portanto, não está na novidade do fenômeno, mas na magnitude e nas características que ele adquire nos tempos atuais. 0 fato de essas fontes de informação aparecerem oito vezes mais que as mídias tradicionais no corpus da hashtag de apoio a Bolsonaro e serem a segunda fonte mais citada entre as mensagens da hashtag crítica ao presidente mostra a importância inequívoca do fenômeno no ecossistema midiático atual. Portanto, apesar dos pontos de inovação das dinâmicas de comunicação frequentemente serem apontados para as mídias sociais, a importância de fontes que as alimentam é evidente. Isso posto, uma análise mais detalhada dessas fontes, que permita a construção de uma tipologia consistente, parece de suma importância.

0 terceiro ponto que nos parece central é a articulação mais ampla entre diferentes espaços de comunicação, que leve em conta outros tipos de mediação. As menções às mídias sociais representam $8 \%$ dos links em ambos os corpora aqui considerados, com larga predominância do Youtube nos dois casos. Apesar da categoria Mídias Sociais nos ser útil nesta pesquisa, onde focamos nas fontes de informação, ela diz pouco sobre quem realmente está falando nessas plataformas. Tipologias de atores em diferentes mídias sociais já foram desenvolvidas (SANTOS, 2019; ALVES, 2019) e precisam ser aprimoradas para que se compreenda de maneira mais precisa essa circulação de conteúdos. Se, de um lado, há um rico ecossistema de websites que alimenta o debate político, de outro, há dinâmicas de sociabilidade, visibilidade e autoridade próprias a cada espaço comunicacional que vão não apenas circular essas informações, mas agregar significados a elas. Não se trata apenas de obter informações de determinadas fontes, mas também de recebê-las através de determinados laços sociais, frequentemente alimentados em mídias digitais. Vale ressaltar, ainda, a importância crucial dos aplicativos de mensagens instantâneas como espaços de circulação dessas mensagens (SANTOS et al., 2019).

Portanto, a atual questão de mediação precisa ser pensada tanto do ponto de vista da sua complexificação a partir dos diversos espaços comunicativos digitais, quanto da forma como essas mediações são diversamente apropriadas pelas diferentes partes da sociedade que buscam construir seus discursos.

Este texto não poderia ser terminado, no entanto, sem apontar as limitações desta pesquisa. Começando pelo fato de que os dados aqui apresentados dizem respeito a um único espaço de comunicação, o Twitter, o que, como apontado acima, apesar de incorporar uma série de processos de escolha, é bastante limitador. Além disso, a forma de coleta das mensagens também representa escolhas que restringem nossos 
resultados a duas hashtags e uma parcela das mensagens. Vale dizer também que as categorias construídas para análise dos links também resultaram de escolhas não evidentes e que certamente podem ser refinadas. De toda forma, acreditamos que os dados e as reflexões aqui apresentados podem indicar importantes caminhos de pesquisa para a compreensão dos atuais processos de mediação e dos papéis sociais dos mediadores, sejam eles os tradicionais atores midiáticos ou aqueles que emergem neste novo contexto. Essa compreensão parece crucial não apenas para apreender a dinâmica comunicacional atual, mas sobretudo seus impactos políticos sobre o funcionamento democrático. 


\section{Referências}

ALDÉ, Alessandra, ESCOBAR, Juliana; CHAGAS, Viktor. A febre dos blogs de política. In: ENCONTRO ANUAL DA COMPÓS, 15. 2006. Anais... Bauru: Compós, 2006.

ALVES, M. Desarranjo da visibilidade, desordem informacional e polarização no Brasil entre 2013 e 2018. 2019. 399f. Tese (Doutorado em Comunicação) - Universidade Federal Fluminense, Niterói, 2019.

AMARAL, Adriana; RECUERO, Raquel; MONTARDO, Sandra (Orgs.). Blogs.com. Um estudo sobre blogs e comunicação. São Paulo: Momento Editorial, 2009.

ATTON, C.; COULDRY, N. Introduction. Media, Culture \& Society, v. 25, p. 579-586, 2003.

BASTOS, M. T.; MERCEA, D. Serial activists: Political Twitter beyond influentials and the twittertariat. New Media \& Society, p.1-20, 2015. DOI: 10.1177/1461444815584764

BENKLER, Y.; FARIS, R.; ROBERTS, H. Network Propaganda. Manipulation, disinformation, and radicalization in American politics. Oxford: Oxford University Press, 2008.

BOYD, D. M.; ELLISON, N. B. Social network sites: definition, history, and scholarship. Journal of ComputerMediated Communication, v. 13, n. 1, out. 2007.

BRUNS, A.; MOE, H. Structural layers of Communication on Twitter. In: BRUNS, A. et al. (Eds.). Twitter and Society. New York: Peter Lang, 2014. p.15-28.

CANAVILHAS, J.; RODRIGUES, C. Jornalismo móvel. Linguagens, géneros e modelos de negócio. Covilhã: LabCom.IFP, 2017.

CASTELLS, Manuel. Communication power. Oxford: Oxford University Press, 2009.

CHADWICK, A. The Hybrid Media System: Politics and Power. Oxford: Oxford University Press, 2013.

ELDRIDGE II, S. A.; GARCÍA-CARRETERO, L.; BROERSMA, M. Disintermediation in Social Networks:

Conceptualizing Political Actors' Construction of Publics on Twitter. Media and Communication, v. 7, n. 1, p. 271, 2019.

FERRON, B. Des médias de mouvements aux mouvements de médias. Mouvements, v. 61, n. 1, p. 107, 2010.

GARCIA, R. G.; TRERE, E. The \#YoSoy132 movement and the struggle for media democratization in Mexico. Convergence, p. 1-15, 2014. DOI: 10.1177/1354856514541744

GERBAUDO, P. Political parties in the digital era. In: DUTTON, W. H. (Ed.). A Research Agenda for Digital Politics. Glos: Edward Elgar Publishing Limited, 2020. p. 37-47. 
GOMES, W.; DOURADO, T. Fake news, um fenômeno de comunicação política entre jornalismo, política e democracia. Estudos de Jornalismo e Mídia, v. 16, n.2, 2019.

Fake news, crise epistêmica e epistemologia tribal. Revista Cult, 8 abr. 2019.

. "Nós somos a rede social!': o protesto político entre as ruas e as redes". In: MENDONÇA, Ricardo F.; PEREIRA, Marcos A.; FILGUEIRAS, Fernando (Eds.). Democracia digital: publicidade, instituições e confronto político. Belo Horizonte: Editora da UFMG, 2016. p.71-394.

HEPP, A. Deep mediatization. Nova lorque: Routledge, 2020.

JOATHAN, İ.; ALVES, M. O Twitter como ferramenta de campanha negativa não oficial: uma análise da campanha eleitoral para a Prefeitura do Rio de Janeiro em 2016. Galáxia, n. 43, p. 81-98, 2020.

LEMOS, A. Epistemologia da comunicação, neomaterialismo e cultura digital. Galáxia, v. 404, n. 43, p. 54-66, 2020.

. As estruturas antropológicas do ciberespaço. In: Cibercultura: tecnologia e vida social na

cultura contemporânea. Porto Alegre: Sulina, 2008. p.127-153

LIVINGSTONE, S. On the Mediation of Everything: ICA Presidential Address 2008. Journal of Communication, v. 59, n. 1, p. 1-18, 2009.

LYCARIÃO, D. Mudanças climáticas sob o prisma da esfera pública: a mediação jornalística como fator de legitimação democrática no caso da COP-15. 334 f. Tese (Doutorado em comunicação) - Universidade Federal de Minas Gerais, 2014.

MARTÍN-BARBERO, J. De los medios a las mediaciones. Comunicación, cultura y hegemonía. Barcelona: Editorial Gustavo Gili, 1987

MERAZ, S.; PAPACHARISSI, Z. Networked gatekeeping and networked framing on \#egypt. The International Journal of Press/Politics, v. 18, n. 2, p. 138-166, 2013.

MITOZO, I. B.; COSTA, G. D. A.; RODRIGUES, C. How do traditional media incorporate statements from political actors in social media ? Brazilian Journalism Research, v. 16, n. 1, p. 152-177, 2020.

MORAES, F. M.; ADGHIRNI, Z. Jornalismo e Democracia: o papel do mediador. E-Compós, v. 14, n. 2, 2012.

NEWMAN, N. et al. Reuters Institute Digital News Report 2019. Oxford: Reuters Institute, 2019.

NIELSEN, R. K. et al. Navigating the 'Infodemic': How People in Six Countries Access and Rate News and Information about Coronavirus. Oxford: Reuters Institute, 2020.

PENTEADO, Claudio L C; SANTOS, Marcelo B. P. dos; ARAUJO, Rafael de P. A. Novas práticas políticas na internet: estudo do Blog Fatos e Dados. In: CONGRESSO DA ASSOCIAÇÃO BRASILEIRA DE PESQUISADORES EM COMUNICAÇÃO POLIITICA, 3., 2009. Anais... São Paulo: Compolítica, 2019. 
PERUZZO, C. M. K. Mídia regional e local: aspectos conceituais e tendências. Comunicação \& Sociedade, v. 26, n. 43, p. 67-84, 2005.

RODRÍGUEZ, C.; FERRON, B.; SHAMAS, K. Four challenges in the field of alternative, radical and citizens' media research. Media, Culture \& Society, v. 36, n. 2, p. 150-166, 2014.

SANTOS, J. G. dos et al. WhatsApp , política mobile e desinformação : a hidra nas eleições presidenciais de 2018. Comunicação e Sociedade, v. 41, n. 2, p. 307-334, 2019.

SANTOS, N. The reconfiguration of the communication environment: Twitter in the 2013 Brazilian protests. 350 f. Tese (Doutorado em ciências da informação e da comunicação) - Université Panthéon-Assas, 2019.

.; ALMADA, M. P. Midiativismo em rede: Twitter e as críticas aos meios de comunicação tradicionais em um sistema híbrido de comunicação. Esferas, n. 14, p. 18-36, 2019.

. Esfera de visibilidade e comunicação desintermediada: uma análise do blog Fatos e Dados. 2010, 85f. Monografia (Graduação em Comunicação Social) - Universidade Federal da Bahia, 2010.

RECUERO, R.; SOARES, F. B. O Discurso Desinformativo sobre a Cura do COVID-19 no Twitter: Estudo de caso. E-Compós, v. 24, 2021.

SCHMIDT, J. H. Twitter and the rise of personal publics. In: BRUNS, A. et al. (Eds.). Twitter and Society. New York: Peter Lang, 2014. p. 3-14.

SEGERBERG, A.; BENNETT, W. L. Social Media and the Organization of Collective Action: Using Twitter to Explore the Ecologies of Two Climate Change Protests. The Communication Review, v. 14, n. 3, p. 197-215, 2011.

SHOEMAKER, P. et al. Individual and routine forces in gatekeeping. Journalism and Mass Communication Quarterly, v. 78, n. 2, p. 233-246, 2001.

SILVA, S. P. DA; MUNDIM, P. S. Mediações no YouTube e o caso 'Ocupação do Complexo do Alemão': características e dinâmica de uso. Intercom - Revista Brasileira de Ciências da Comunicação, v. 38, n. 1, p. 231-253, 2015.

STIER, S.; SCHÜNEMANN, W. J.; STEIGER, S. Of activists and gatekeepers: Temporal and structural properties of policy networks on Twitter. New Media and Society, v. 20, n. 5, p. 1910-1930, 2018.

SUZINA, A. Is mediactivism a kind of poor journalism?. In: 12th OURMedia Conference, Bruxelas, 2019.

Anais... Bruxelas: UORMedia, 2019.

THOMPSON, J. B. The New Visibility. Theory, Culture \& Society, v. 22, n.6, p. 31-51, 2005.

WAISBORD, S. Bridging the Divide between the Press and Civic Society. Nordicom Review, n. Jubilee Issue, p. 105-116, 2009. 


\section{Informações sobre 0 artigo}

\section{Resultado de projeto de pesquisa, de dissertação, tese}

0 artigo é resultado da pesquisa "Mediação, visibilidade e autoridade na era da comunicação digital" realizada no âmbito do projeto de pós-doutorado no Instituto Nacional de Ciência e Tecnologia em Democracia Digital.

\section{Fontes de financiamento}

Bolsista Capes - Processo 88887.368694/2019-00

\section{Considerações éticas}

Não se aplica.

\section{Declaração de conflito de interesses}

Não se aplica.

\section{Apresentação anterior}

Não se aplica.

\section{Agradecimentos/Contribuições adicionais}

Agradeço às contribuições feitas pelos professores Viktor Chagas e Rayza Sarmento e pelos colegas do grupo de pesquisa em Comunicação, Internet e Democracia, coordenado pelo professor Wilson Gomes, às versões preliminares deste texto. 